\title{
Editorial: A New Bright Era for Evolutionary Medicine
}

\author{
Konstantinos Voskarides ${ }^{1}$ (D)
}

Received: 13 November 2019 / Accepted: 18 November 2019 / Published online: 11 December 2019

(c) Springer Science+Business Media, LLC, part of Springer Nature 2019

\begin{abstract}
Evolutionary Medicine is a fast-growing research field providing biomedical scientists with valuable information on molecular and pathophysiological mechanisms of disease. Evolutionary theory explains many medical conditions and it can contribute to new innovative treatments. This is the reason that Journal of Molecular Evolution has devoted this issue to Evolutionary Medicine. Nine detailed review papers are included in this issue, analyzing topics that are among the "hottest" subjects of Evolutionary Medicine. All information is up to date and highly valuable for scientists that would like to start their career or get updated on this field.
\end{abstract}

Keywords Evolutionary genetics $\cdot$ Natural selection $\cdot$ Cancer $\cdot$ Evolution $\cdot$ Molecular evolution

Charles Darwin, the founder of evolution and natural selection, did not discuss in any of his manuscripts the implications of his theory in health (Darwin 1859). Because of his general insightfulness, one would imagine that he could realize the consequences of his theory in medicine. However, in the nineteenth century, his priority was to convince people that natural selection and adaptation are the founding principles of life in Earth. Today, having vast evidence about the process of evolution, we can proceed much further. Modern genetics provided biologists with thousands of genomes, from individuals, with sampling reaching the population level. We are now aware of multiple genes that are under positive or negative selection, many of them also linked with disease. Evolutionary Medicine is a fast-growing research field providing biomedical scientists with valuable information on molecular and pathophysiological mechanisms of disease. This is the reason that Journal of Molecular Evolution has devoted this issue to Evolutionary Medicine. Nine detailed review papers are included in this issue, analyzing topics that are among the "hottest" subjects of Evolutionary Medicine. All information is up to date and highly valuable for scientists that would like to start their career or get updated on this field.

Handling Editor: David Liberles.

Konstantinos Voskarides

kvoskar@ucy.ac.cy

1 Medical School, University of Cyprus, Nicosia, Cyprus
The first scientist that linked evolution with health was George Williams, about 100 years after publication of Darwin's theory on natural selection. He hypothesized that senescence is a consequence of evolutionary mechanisms (Williams 1957). He introduced many other interesting theories on how Darwinian processes interfere with human health. One of the best known is antagonistic pleiotropy, a theory that only recently became established. An interesting review paper dealing with this issue in humans can be found in this special journal issue (Byars and Voskarides 2019). Two other reviews analyze the evolution of animal pathogens, viruses, and bacteria, discussing how this knowledge help us to explain disease epidemics and antibiotic resistance (Christaki et al. 2019; Kaján et al. 2019). Infectious disease pandemics and antibiotic resistance are of great concern for medical doctors today since these may become the reason of thousands or millions of deaths in the near future.

George Williams was the first to link evolution with aging. Genetics provides biologists today with significant evidence about how DNA is linked with aging. It is quite interesting that lifespan and longevity differ vastly across species and this provides clues about evolutionary pressures. An interesting review in this special issue discusses the possible consequences of evolution on aging and human lifespan (Kyriazis 2019). Three other more specific reviews analyze the subjects of human skin pigmentation, immune system response and thyroid gland function. These papers discuss intriguing questions like the following: "Why did IgE evolve" (Daschner and Fernandez 2019), "Why there is 
such a great variety of human skin pigmentation?" (Rocha 2019), "Why thyroxine cannot repair and regenerate mammal tissues as in invertebrates?" (Mourouzis et al. 2019). The last paper of this journal special issue discusses the evolutionary and medical significance of Copy Number Variations (CNVs) in humans (Saitou and Gokcumen 2019). These large genetic rearrangements providing duplicate gene copies have been linked with a variety of human multifactorial diseases.

I would like to mention here the contribution of Randolph Nesse and Stephen Stearns on Evolutionary Medicine. These scientists have greatly contributed to the field of Evolutionary Medicine and they are considered by many as the founders of the modern field. Prof. Stephen Stearns wrote a special article for this journal issue, analyzing most of the great recent advances of the field (Stearns 2019).

Evolutionary Medicine is now at a critical point of development. Molecular Biology provided many tools for a research progress. Results of such studies are already applicable in clinical medicine. The next step in medicine is about looking for the "cause of the cause" instead of just looking for the cause.

\section{References}

Byars SG, Voskarides K (2019) Antagonistic pleiotropy in human disease. In Press, J Mol Evol

Christaki E, Marcou M, Tofarides A (2019) Antimicrobial resistance in bacteria: mechanisms, evolution, and persistence. In Press, J Mol Evol

Darwin CR (1859) On the origin of species by means of natural selection, or the preservation of favoured races in the struggle for life. John Murray, London

Daschner A, Fernandez JG (2019) Allergy in an evolutionary framework. In Press, J Mol Evol

Kaján GL, Doszpoly A, Tarján ZL, Vidovszky MZ, Papp T (2019) Virus-host coevolution with a focus on animal and human DNA viruses. In Press, J Mol Evol

Kyriazis M (2019) Ageing throughout history: the evolution of human lifespan. In Press, J Mol Evol

Mourouzis I, Lavecchia AM, Xinaris C (2019) Thyroid hormone signalling: from the dawn of life to the bedside. In Press, J Mol Evol

Rocha J (2019) The evolutionary history of human skin pigmentation. In Press, J Mol Evol

Saitou M, Gokcumen O (2019) An evolutionary perspective on the impact of genomic copy number variation on human health. In Press, J Mol Evol

Stearns SC (2019) Frontiers in molecular evolutionary medicine. In Press, J Mol Evol

Williams GC (1957) Pleiotropy, natural selection, and the evolution of senescence. Evolution 11:398-411 